\title{
Processos logográficos, alfabéticos e lexicais na leitura silenciosa por surdos e ouvintes ${ }^{1}$
}

\author{
Fernando Capovilla \\ Universidade de São Paulo \\ Alessandra Gotuzo Seabra Capovilla \\ Universidade São Francisco \\ Keila Viggiano \\ Aline Mauricio \\ Márcia Bidá \\ Universidade de São Paulo
}

\begin{abstract}
Resumo
O estudo empregou o Teste de Competência de Leitura de Palavras (TCLP) para analisar estratégias ideovisuais, perilexicais e lexicais de leitura por 805 escolares surdos de 6-45 anos, da $1^{\underline{a}}$ série do ensino fundamental à $1^{\text {a }}$ série do médio. Identificou aumento sistemático na competência de leitura de $1^{\underline{a}}$ a $5^{\underline{a}}$ séries, além de aumentos assistemáticos até a $1^{\underline{a}}$ série do ensino médio, e comparou padrões de erros nos subtestes. Resultados revelaram dissociações duplas entre leitores surdos e ouvintes quanto ao padrão de erros nos subtestes: enquanto ouvintes se deixam enganar mais pela semelhança fonológica, surdos se deixam enganar mais pela visual. Enquanto ouvintes privilegiam a forma ortográfica em detrimento da correção semântica, surdos fazem o oposto. Devido à dificuldade de surdos em fazer conferência perilexical, sua leitura mostrou-se dependente de mecanismos visuais diretos de reconhecimento e acesso ao significado. O TCLP revelou-se instrumento válido para avaliar a leitura de surdos.
\end{abstract}

Palavras-chave: leitura; avaliação; surdez; língua de sinais; linguagem

\begin{abstract}
Silent reading by deaf and hearing readers: logographic, alphabetical and lexical processes. The study used Word Reading Competence Test to analyze ideovisual, perilexical and lexical reading strategies by 805 6-45 year-old deaf students from $1^{\text {st }}$ to $9^{\text {th }}$ grade $\left(1^{\text {st }}\right.$ grade elementary school to $1^{\text {st }}$ grade high school). It identified a systematic increase in reading competence from $1^{\text {st }}$ to $5^{\text {th }}$ grade, and non-systematic increases until $9^{\text {th }}$ grade. Results revealed double dissociation between deaf and hearing readers regarding error patterns across subtests: Hearing readers tended to be fooled more by phonological similarity than by visual similarity, whereas the opposite was found with deaf readers. Also, the hearing readers relied more on orthographic form than on semantic adequacy, whereas deaf readers did the opposite. Therefore, deaf reading was shown to depend essentially upon visual direct word recognition and semantic access mechanisms due to poor efficacy of perilexical checking mechanisms. Word Reading Competence Test was shown to be a valid instrument for assessing reading in deaf students.
\end{abstract}

Keywords: reading; assessment; deafness; sign language; language

\section{A aquisição da linguagem escrita}

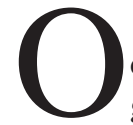
modelo de desenvolvimento da linguagem escrita de Frith (1990) e Morton (1989) identifica três estágios distintos na alfabetização, durante os quais se desenvolvem diferentes rotas ou estratégias de leitura. No primeiro estágio, o logográfico, desenvolve-se a estratégia logográfica. Nessa fase, a criança faz reconhecimento visual direto de certas propriedades gerais da palavra escrita com base no contexto, na forma e na cor, mas não atenta à composição precisa das letras que formam a palavra, exceto usual- 
mente pela primeira letra. Assim, por exemplo, se forem trocadas as letras $\mathrm{D}$ por $\mathrm{B}, \mathrm{N}$ por $\mathrm{M}$, e $\mathrm{D}$ por $\mathrm{P}$ na palavra escrita MCDONALD'S, a criança não tenderá a notar a troca, desde que haja arcos dourados sobre um fundo vermelho. A criança trata as palavras escritas como se fossem desenhos e só consegue reconhecer as palavras com as quais está bastante familiarizada, sendo incapaz de penetrar na composição grafêmica das palavras ou de ler palavras novas. Tal leitura de natureza icônica e ideográfica limita-se ao reconhecimento do aspecto geral de palavras muito familiares.

No segundo estágio, o alfabético, desenvolve-se a rota ou estratégia fonológica. Nessa fase, a criança aprende a fazer decodificação grafofonêmica e passa a decodificar pseudopalavras e palavras novas (i.e., palavras cuja forma ortográfica ainda não é familiar). Contudo, o uso desta estratégia só é bem sucedido se a criança dominar a habilidade de decodificação grafofonêmica e se as palavras a serem lidas forem regulares grafofonemicamente, de modo que a imagem fonológica resultante da decodificação soe familiar à criança, ou seja, soe como uma das palavras conhecidas já armazenadas em seu léxico auditivo lingüístico (i.e., léxico fonológico). A decodificação de palavras grafofonemicamente irregulares tende a produzir erros de regularização fonológica e falhas de compreensão de leitura. Crianças com dislexia fonológica mostram grande dificuldade em empreender decodificação grafofonêmica competente, o que ocorre em $67 \%$ dos casos de dislexia do desenvolvimento (Boder, 1973; F. Capovilla \& Capovilla, 2004), e usualmente tentam adivinhar o que está escrito, cometendo freqüentes paralexias.

No terceiro estágio, o ortográfico, desenvolve-se a rota ou estratégia lexical. Nessa fase a criança aprende a ler lexicalmente, fazendo reconhecimento visual direto da forma ortográfica das palavras, e torna-se capaz de ler palavras grafofonemicamente irregulares, não mais cometendo erros de regularização grafofonêmica, desde que as palavras a serem lidas sejam comuns e que a criança esteja familiarizada com elas. As crianças com dislexia morfêmica têm dificuldade em fazer esse reconhecimento visual direto da forma ortográfica das palavras, o que ocorre em cerca de $10 \%$ dos casos de dislexia.

Para Frith (1990), a dislexia do desenvolvimento pode ser compreendida como uma espécie de interrupção na progressão de uma a outra fase ao longo do desenvolvimento da leitura. Tal interrupção pode ocorrer já na passagem do estágio logográfico para o alfabético, como no caso da dislexia fonológica; ou apenas na passagem do alfabético para o ortográfico, como no caso assim chamada da dislexia morfêmica. No primeiro caso a dificuldade constitui um distúrbio de desenvolvimento propriamente dito, fruto de disfunção fonológica freqüentemente com substrato constitucional definido; ao passo que, no segundo caso, a dificuldade constitui mais um atraso de desenvolvimento do que propriamente um distúrbio, sendo o prognóstico consideravelmente melhor (Capovilla \& Capovilla, 2004b).

Apesar dos grandes avanços na compreensão da aquisição e dos distúrbios da linguagem escrita, até meados da década de 1980, não havia qualquer consenso, no campo de educação de surdos, quanto à melhor forma de desenvolver leitura e escrita, apesar das evidências sobre a dificuldade de leitura apresentada pelos surdos (Clark, Marschark, \& Karchmer, 2001). Isso só começou a mudar na década de 1990. Por exemplo, Luetke-Stahlman, Hayes e Nielsen (1996) conduziram uma revisão da literatura sobre as práticas de ensino de leitura com vistas a identificar as mais promissoras e orientar professores e pais sobre como empregá-las. LuetkeStahlman et al. confessaram-se especialmente impressionados com o trabalho de Adams (1990), com respeito às práticas comprovadamente capazes de promover leitura proficiente em estudantes ouvintes, e com o trabalho de Hoggan e Strong (1994), que estudaram as técnicas daqueles que trabalham com estudantes com deficiências. A propósito, as principais conclusões do trabalho de Adams, tais como aplicadas à alfabetização em Português, encontram-se em Cardoso-Martins et al. (2003). O resultado dessa revisão bibliográfica foi um quadro teórico-conceptual e uma descrição das dez práticas consideradas essenciais para o ensino de leitura proficiente, com especial ênfase em programas que empregam métodos de leitura em voz alta, leitura compartilhada entre adultos e crianças, e leitura guiada por adultos, nos quais os professores servem de modelo para pais e monitores dedicados a desenvolver habilidade de leitura na criança surda.

Além das práticas de leitura em voz alta, leitura compartilhada entre adultos e crianças, e leitura guiada por adulto, o estudo de Gillespie e Twardosz (1996) levantou diversas práticas de ensino de leitura que vêm sendo empregadas em escolas para surdos no regime de internato espalhadas nos Estados Unidos. Tais práticas incluem leitura para a criança, supervisão do dever de casa e acompanhamento da leitura independente e da escrita de cartas. Os autores recomendam que as escolas reservem períodos específicos à leitura de livros de estórias, promovam atividades em grupo como as de contar estórias e ler livros de estórias, e que façam rodízio de livros e outros materiais de leitura, de modo a manter o interesse e a motivação das crianças.

Um estudo subseqüente de Gillespie e Twardosz (1997) demonstrou que a leitura conjunta de livros de estórias em que os leitores usam um estilo expressivo e interativo é fundamental para promover a leitura independente fora da sala de aula. Nesse estudo com 18 surdos de 4 a 11 anos, foi observado que os estudantes surdos que participaram de um programa de 40 sessões (i.e., duas vezes por semana durante cinco meses) de leitura de livros de estórias em grupo apresentaram leitura mais independente e maior interesse em livros do que seus colegas que não participaram do programa. As sessões de leitura conjunta de livros de estórias em que os leitores usam um estilo expressivo e interativo maximizam o efeito do rodízio de livros em manter o engajamento dos alunos surdos.

Com o objetivo de analisar a aquisição de leitura e escrita pelo surdo no português brasileiro, no presente estudo, alunos surdos foram expostos a um teste de leitura. O estudo analisou as estratégias usadas por escolares surdos desde o 
início do ensino fundamental até o ensino médio, em termos do modelo de estágios logográfico, alfabético e ortográfico, e comparou as estratégias dos surdos com as dos ouvintes. Tal análise do desenvolvimento da leitura em escolares surdos é fundamental para desenvolver condições mais eficazes para ensinar leitura e escrita, e comparar a eficácia de diferentes metodologias de alfabetização sobre o desempenho em leitura. Com a pesquisa e desenvolvimento de instrumentos de avaliação e intervenção, objetiva-se ultrapassar o estágio primário de discussão de ideologias e abordagens de ensino, rumo a uma abordagem matricial, em que se busca prescrever os procedimentos mais adequados para educandos surdos brasileiros com diferentes características individuais.

O estudo teve quatro objetivos: (1) descrever o desenvolvimento, ao longo da escolarização (i.e., da $1^{\underline{a}}$ série do ensino fundamental até a $1^{\underline{a}}$ série do ensino médio), da competência de leitura silenciosa de itens escritos isolados; (2) avaliar se a versão original do Teste de Competência de Leitura de Palavras (TCLP) é capaz de discriminar entre as nove séries escolares sucessivas; (3) comparar o desempenho de surdos da presente amostra ao de ouvintes de amostras anteriores; e (4) obter subsídios para empreender a validação de construto do TCLP por meio da análise das relações entre os escores dos seus subtestes, de modo a checar se a configuração dos escores nesses subtestes é compatível com as expectativas teóricas acerca do funcionamento das três rotas no surdo e no ouvinte.

\section{Método}

\section{Participantes}

Participaram voluntariamente deste estudo 805 crianças, jovens e adultos surdos, de 6 a 45 anos de idade, estudantes de $1^{\underline{a}}$ série do ensino fundamental até a $1^{\underline{a}}$ série do ensino médio, provenientes de quatro escolas municipais de educação especial de São Paulo e de duas escolas filantrópicas do interior do estado de São Paulo. Dos 805, 700 estudavam em escolas especiais para surdos, 80 em classes regulares de escolas regulares e 25 em classes especiais. Estas últimas 105 crianças não recebiam ensino em Libras, mas apenas ensino comum em Português, e tinham pouca oportunidade de contato com a Libras e a comunidade surda.

Dos 805 estudantes, 26 não tinham série escolar definida, pois pertenciam a classes especiais que seguem programas e regimes diferentes. Dos demais, 103 cursavam a $1^{\underline{a}}$ série do ensino fundamental; 110 , a $2^{\underline{a}}$ série; 129 , a $3^{\underline{a}}$ série; 135 , a $4^{\underline{a}}$ série; 83 , a $5^{\underline{a}}$ série; 91 , a $6^{\underline{a}}$ série; 71 , a $7^{\underline{a}}$ série; 50 , a $8^{\underline{a}}$ série; e 7 , a $1^{\underline{a}}$ série do ensino médio. A escolaridade média desses 779 estudantes era de 4,07 anos (desvio-padrão, $D P=2,14$ ), ou seja, $4^{\underline{a}}$ série.

Dos 805 prontuários, 774 tinham dados sobre idade, que variou de 6 a 45 anos, com média de 14a2m (14 anos e 2 meses e $D P=4,87)$. Dos 805, 781 tinham dados de gênero, sendo que 434 eram do gênero masculino e 347, feminino. Dos 805 estudantes, 282 tinham escolaridade paterna conhecida, que variou de 0 a 15 anos, com média de 6a2m ( $D P=3,39)$, e 319 tinham escolaridade materna conhecida, que foi de $5 \mathrm{a} 11 \mathrm{~m}$ $(D P=3,18)$. Dos 805 estudantes, 76 tinham idade da aquisição da língua de sinais conhecida, que foi de 5a7m ( $D P=$ $3,18)$. Seis tinham idade de aquisição de oralização conhecida, que foi de $4 \mathrm{a} 8 \mathrm{~m}(D P=1,5)$.

Dos 805 prontuários, apenas 757 tinham grau de perda auditiva mencionada, embora em sua maioria não estabelecida a partir de exames audiológicos precisos. Numa escala aproximada de severidade variando de 1 a 4 (sendo 1 = leve, $2=$ moderada, 3 = severa, 4 = profunda) a média foi de 3,72 (DP $=0,56)$. Segundo os registros, dos 805 surdos, 407 faziam uso de aparelho auditivo e 81 não, não havendo dados para os restantes 317. Dos 4 surdos com perda leve, 2 declararam usar aparelho auditivo e 2 não. Dos 55 com perda moderada, 33 declararam usar aparelho e 7 não. Dos 133 com perda severa, 79 declararam usar aparelho e 11 não. Dos 562 com perda profunda, 290 declararam usar aparelho e 60 não. Com relação ao tipo de perda auditiva (congênita ou adquirida), dos 805 estudantes, 553 tinham algum tipo de perda declarada, sendo que, destes, 422 declararam ter perda congênita (quatro casos de perda leve, 31 casos de moderada, 83 casos de severa e 304 casos de profunda) e 131 declararam ter perda adquirida (10 casos de perda moderada, 21 casos de severa e 100 casos de profunda).

Quanto ao modo de comunicação com a família em casa, dos 805 surdos, 476 nada declararam. Os 329 restantes revelaram fazer uso dos seguintes recursos: sinais (124 casos); sinal e oralização (85); oralização (61); sinal, oralização e escrita (31); gestos (18); sinal e gesto (8); oralização e gesto (1); e sinal e escrita (1). Quanto ao modo de comunicação na escola, dos 805 surdos, 543 nada declararam. Os 262 restantes revelaram que fazem uso dos seguintes recursos: sinais (136 casos); oralização (55); sinal e oralização (55); gestos (9); sinal, oralização e escrita (3); oralização e gesto (2); sinal e gesto (1); e sinal e escrita (1). Quanto ao modo de comunicação com a comunidade de amigos, dos 805 surdos, 609 nada declararam. Os 196 restantes revelaram que fazem uso dos seguintes recursos: sinais (100 casos); oralização (37); oralização e leitura (27); sinal e oralização (21); gestos (3); sinal e gesto (3); sinal, oralização e escrita (2); oralização e gesto (2); e sinal e escrita (1). Assim, conforme os prontuários, o uso de oralização e de gestos tendeu a diminuir com a passagem do ambiente familiar para o escolar e deste para o da comunidade social. Ao mesmo tempo, o uso de sinais tendeu a aumentar com a passagem do ambiente familiar para o escolar. Tais dados sobre a importância da língua de sinais são compatíveis com os dados canadenses de Karchmer, Allen, Petersen e Quaynor (1982), quanto a idade, sexo, grau de perda auditiva, causa e idade de surgimento da surdez, e tipo de língua falada em casa por 4.083 estudantes com deficiência auditiva em escolas residenciais para surdos, escolas diurnas para surdos, classes de educação especial em tempo integral, e programas de tempo parcial. 


\section{Instrumento}

O Teste de Competência de Leitura Silenciosa de Palavras - TCLP (Capovilla \& Capovilla, 2004a; Capovilla \& Capovilla, 2001; Capovilla et al., no prelo) avalia o estágio de desenvolvimento da leitura ao longo das etapas logográfica, alfabética e ortográfica. Trata-se de um teste de papel e lápis eficientemente implementado em um caderno de aplicação, e há também uma versão computadorizada para avaliar crianças surdas com distúrbios neuromotores. O TCLP é acompanhado de tabelas de normatização para avaliar o grau de desvio entre o padrão de leitura de um dado examinando e o padrão de leitura normal de seu grupo de referência de acordo com o nível de escolaridade.

O teste permite interpretar os dados do padrão de leitura específico apresentado por uma criança no que concerne ao modelo do desenvolvimento de leitura e escrita, e inferir as estratégias de leitura (i.e., ideovisual ou logográfica, perilexical ou fonológica, lexical) usadas, de modo a compreender a natureza da dificuldade específica de um determinado examinando. Ele foi inspirado no paradigma geral esboçado por Khomsi (1997) e aperfeiçoado por Braibant (1997). Contém 8 itens de treino e 70 itens de teste reunidos num caderno de aplicação. Cada item é composto de uma figura e um elemento escrito. Esse elemento escrito pode ser uma palavra ou uma pseudopalavra. Pseudopalavras são seqüências de caracteres que compõem um todo pronunciável, mas carente de significado. Os elementos escritos são apresentados em letras maiúsculas para permitir manipular o efeito da similaridade visual. A tarefa do examinando é circundar os itens corretos e cruzar (i.e., assinalar com um "X”) os itens incorretos, ou seja, aqueles em que há disparidade semântica entre a figura e o elemento escrito, ou disparidade ortográfica no elemento escrito.

Há sete tipos de item, todos distribuídos aleatoriamente ao longo do teste, com dez itens de teste para cada tipo de par. São eles: 1) Tipo 1 (CR: Corretas Regulares): Palavras ortograficamente corretas, semanticamente corretas e grafofonemicamente regulares, a serem aceitas, como a palavra escrita FADA sob a figura de fada; Tipo 2 (CI: Corretas Irregulares): Palavras ortograficamente corretas, semanticamente corretas e grafofonemicamente irregulares, a serem aceitas, como a palavra escrita TÁXI sob figura de táxi; Tipo 3 (VS: Vizinhas Semânticas): Palavras ortograficamente corretas, mas semanticamente incorretas, a serem rejeitadas, como a palavra escrita CACHORRO sob figura de rato; Tipo 4 (VV: Vizinhas Visuais): Pseudopalavras ortograficamente incorretas, com trocas visuais, a serem rejeitadas, como a pseudopalavra escrita CAEBÇA sob figura de cabeça; Tipo 5 (VF: Vizinhas Fonológicas): Pseudopalavras ortograficamente incorretas, com trocas fonológicas, a serem rejeitadas, como a pseudopalavra escrita MÁCHICO sob figura de mágico; Tipo 6 (PH: Pseudopalavras Homófonas): Pseudopalavras ortograficamente incorretas a serem rejeitadas, embora homófonas a palavras semanticamente corretas, como a pseudopalavra escrita PÁÇARU sob figura de pássaro; Tipo 7 (PE: Pseudopalavras Estranhas): Pseudopalavras ortograficamente incorretas e estranhas, tanto fonologicamente quanto visualmente, a serem rejeitadas, como a pseudopalavra escrita XUNVACO sob figura de sanfona.

A Figura 1 ilustra sete pares compostos de figura e item escrito, que exemplificam cada um dos sete tipos de pares que compõem a versão original do TCLP.

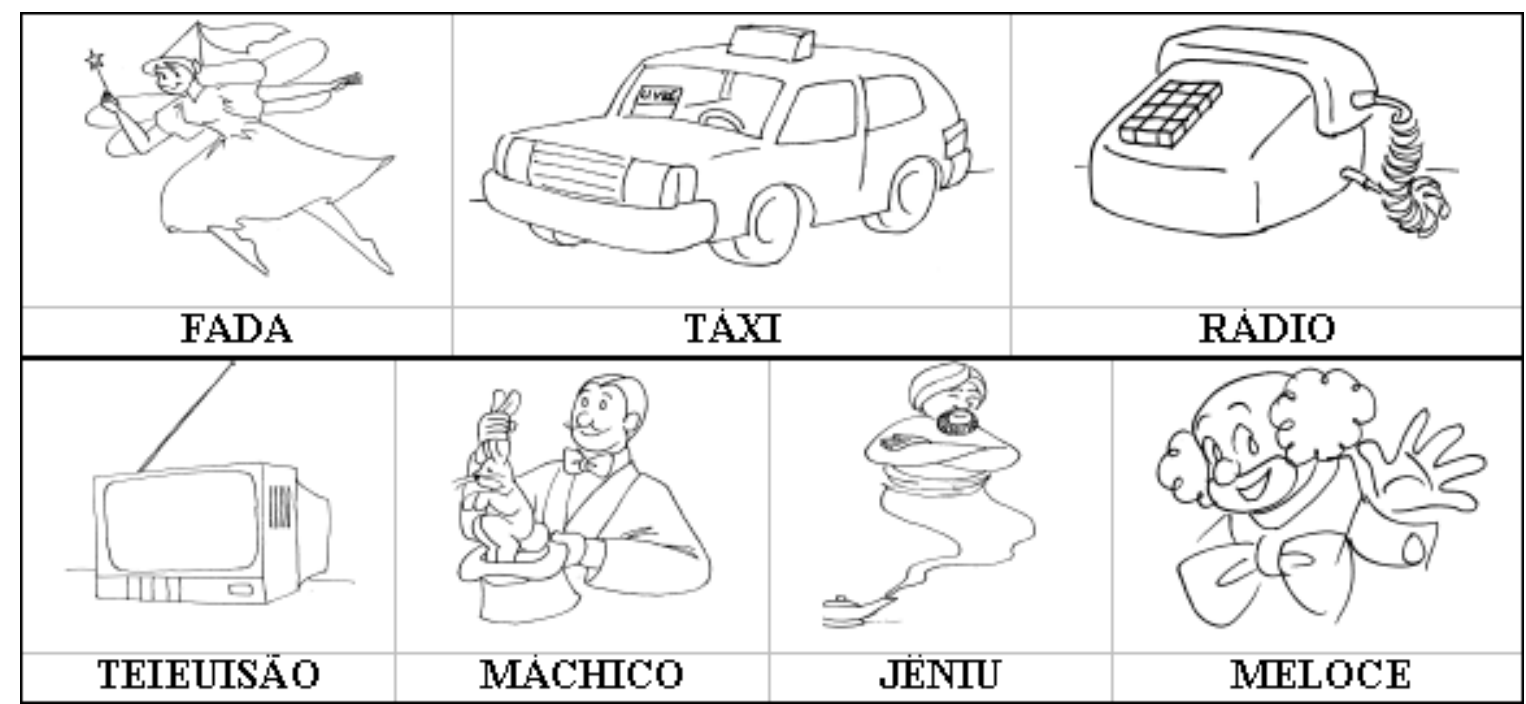

Figura 1. Exemplos de cada um dos sete tipos de pares de figura e escrita da versão original do Teste de Competência de Leitura de Palavras (TCLP1.1): Duas palavras corretas, uma regular (Tipo 1 ou CR: FADA) e uma irregular (Tipo 2 ou CI: TÁXI), uma palavra com incorreção semântica (Tipo 3 ou VS: RÁDIO sob figura de telefone), uma pseudopalavra com troca visual (Tipo 4 ou VV: TEIEUISÃO) e uma com troca fonológica (Tipo 5 ou VF: MÁCHICO), uma pseudopalavra homófona (Tipo 6 ou PH: JÊNIU) e uma pseudopalavra estranha (Tipo 7 ou PE: MELOCE). 
Os pares compostos de palavras ortograficamente corretas e semanticamente corretas, quer grafofonemicamente regulares (tipo 1) ou irregulares (tipo 2), devem ser aceitos (i.e., circulados com o lápis). Os pares compostos de palavras com incorreção semântica (tipo 3) ou de pseudopalavras (i.e., tipos 4, 5, 6 e 7) devem ser rejeitados (i.e., cruzados com “ $X$ ”).

O padrão de distribuição dos tipos de erros revela a natureza específica do processamento cognitivo do examinando e indica as estratégias de leitura que ele consegue usar e aquelas com que tem dificuldade. Assim, esse padrão tem elevado valor informativo para caracterizar a natureza particular da dificuldade de leitura de um determinado examinando.

Os pares figura-escrita compostos de palavras corretas regulares e irregulares devem ser aceitos, ao passo que aqueles compostos de palavras com incorreção semântica ou de pseudopalavras devem ser rejeitados. O erro de rejeitar pares com palavras corretas irregulares (CI) pode indicar dificuldade com o processamento lexical ou falta dele. O erro de deixar de rejeitar pseudopalavras homófonas $(\mathrm{PH})$ também pode indicar dificuldade no processamento lexical, porém em nível mais acentuado, com uso exclusivo da rota fonológica. O erro de deixar de rejeitar pseudopalavras com trocas fonológicas (VF) pode indicar que a criança está tentando ler exclusivamente pela rota fonológica, ou seja, pela decodificação grafofonêmica estrita, sem fazer uso da rota lexical, mas com o agravante de dificuldades com o processamento fonológico. O erro de deixar de rejeitar palavras semanticamente incorretas (VS) indica que a criança não está fazendo acesso ao léxico semântico. O erro de deixar de rejeitar pseudopalavras com trocas visuais (VV) pode indicar dificuldade com o processamento fonológico, e recurso à estratégia de leitura logográfica. Finalmente, o erro de deixar de rejeitar pseudopalavras estranhas (PE) pode sugerir problemas sérios de leitura ou atenção. Devido às relações intrínsecas aos sete tipos de pares figura-escrita, é possível fazer checagem das conclusões e validação cruzada das evidências fornecidas em cada tipo de par figura-escrita do TCLP.

Neste estudo, pela primeira vez, o TCLP foi aplicado a crianças surdas. A validade da versão tradicional do teste em mapear o processamento cognitivo de leitura em crianças ouvintes foi estabelecida em uma série de estudos recentemente publicados (Capovilla \& Capovilla, 2004a; Capovilla \& Capovilla, 2001, 2004) demonstrando que crianças que pontuam na faixa igual ou inferior a um desvio padrão abaixo da média no TCLP apresentam maior dificuldade em discriminar fonemas, menor velocidade de processamento fonológico e menor capacidade de memória de trabalho fonológica (Capovilla \& Capovilla, 2001), consciência fonológica (Capovilla \& Capovilla, no prelo b), vocabulário (Capovilla \& Capovilla, 1997; Capovilla et al., 1997), ditado e desenho de memória (Capovilla, Smythe, Capovilla, \& Everatt, 2001). Além disso, o TCLP mostrou-se sensível à escolaridade, sendo capaz de discriminar entre séries sucessivas da $1^{\underline{a}}$ à $3^{\underline{a}}$ série (Capovilla, Machalous, \& Capovilla, 2003), além de fidedigno, sendo que os escores na pré-escola predizem de modo confiável os escores obtidos um ano depois, na $1^{\underline{a}}$ série (Capovilla, Gütschow, \& Capovilla, 2003).

\section{Procedimento}

O instrumento foi aplicado por uma psicóloga fluente em Libras em situação coletiva, nas próprias salas de aula dos participantes, durante o período escolar regular. Como havia heterogeneidade no conhecimento de Libras e de português falado por parte dos participantes, as instruções foram dadas em Libras e em português para todas as classes.

\section{Resultados}

\section{Efeito de série escolar sobre escore total na versão original do TCLP}

A análise de covariância do escore total no TCLP como função da série escolar, tendo como covariante a idade dos escolares em meses, revelou efeito significativo da série escolar, $F_{(8,737)}=30,93, p<0,000, N=747$, bem como do covariante idade, $F_{(1,737)}=11,48, p<0,001$. Nesta análise foram considerados somente os dados de 747 participantes, visto que os demais não apresentavam série escolar definida e/ou dados sobre idade nos prontuários escolares. Conforme sumariado na Tabela 1 , o escore aumentou desde a $1^{\underline{a}}$ série do ensino fundamental até a $1^{1}$ série do ensino médio. As análises de comparação de pares por meio do teste de Bonferroni revelaram que o escore cresceu significativamente da $1^{\text {ạ }}$ série a todas as demais já a partir da $2^{\underline{a}}$ série; da $2^{\underline{a}}$ série a todas as demais já a partir da $3^{\underline{a}}$ série; da $3^{\underline{a}}$ série a todas as demais já a partir da $4^{\underline{a}}$ série; e da $4^{\underline{a}}$ série a todas as demais a partir da $6^{\underline{a}}$ série. Não houve diferença significativa a partir da $5^{\underline{a}}$ série.

\section{Tabela 1}

Escore total na versão 1.1 do Teste de Competência de Leitura de Palavras (TCLP 1.1) em função da série escolar, controlando o efeito da variação de idade, em anos, por meio da análise de covariância (ANCOVA)

\begin{tabular}{cccc}
\hline Série & $\begin{array}{c}\text { Média ajustada } \\
\text { pela ANCOVA }\end{array}$ & $\begin{array}{c}\text { Erro padrão obtido } \\
\text { da ANCOVA }\end{array}$ & N \\
\hline $1^{\underline{\underline{a}}}$ & 36,22 & 1,04 & 98 \\
$2^{2^{\underline{a}}}$ & 40,92 & 0,96 & 109 \\
$3^{\underline{\underline{a}}}$ & 45,75 & 0,83 & 128 \\
$4^{\underline{\underline{a}}}$ & 49,87 & 0,80 & 133 \\
$5^{\underline{\underline{a}}}$ & 53,97 & 1,04 & 81 \\
$6^{\underline{\underline{a}}}$ & 54,31 & 1,08 & 83 \\
$7^{\underline{\underline{a}}}$ & 56,20 & 1,23 & 68 \\
$8^{\underline{\underline{a}}}$ & 59,52 & 1,54 & 40 \\
$9^{\underline{\underline{a}}}$ & 61,39 & 3,51 & 7 \\
\hline
\end{tabular}

\section{Processamento ideovisual, fonológico e semântico no TCLP}

Esta seção compara a distribuição de acertos na rejeição de itens incorretos (VS, PE, PH, VF e VV) por surdos e ouvintes. Para tanto foram considerados, para os surdos, apenas os dados de $1^{\underline{a}}$ a $8^{\underline{a}}$ série do ensino fundamental $(n=740)$, devido ao pequeno número de participantes da $1^{\underline{a}}$ série do ensino médio $(n=7)$ e à grande variabilidade das pontuações 
( $E P=3,5$ pontos). O padrão de acertos médios ao longo dos cinco subtestes apresentado pelos leitores surdos foi o seguinte: VS $(8,4)>\mathrm{PE}(8,0)>\mathrm{PH}(7,4)>\mathrm{VF}(6,5)>\mathrm{VV}(6,0)$. Tal padrão discrepou daquele dos leitores ouvintes, o qual fora estabelecido com uma amostra de mais de mil leitores ouvintes de $1^{\underline{a}}$ a $3^{\underline{a}}$ séries do ensino fundamental (Capovilla \& Capovilla, no prelo a), que havia sido o seguinte: PE $(9,2)>$ $\mathrm{VS}(8,8)>\mathrm{VV}(7,9)>\mathrm{VF}(6,9)>\mathrm{PH}(5,9)$. A Figura 2 representa a pontuação média nos cinco tipos de subteste por parte da amostra de mil leitores ouvintes de $1^{\underline{a}}$ a $3^{\text {a }}$ séries (do estudo de Capovilla \& Capovilla, no prelo a) e da presente amostra como um todo de 740 surdos de $1^{\underline{a}}$ a $8^{\underline{a}}$ séries com idades conhecidas. Nesse estudo, a pontuação média foi de 48,4 pontos na $1^{\underline{a}}$ série, 57,5 pontos na $2^{\underline{a}}$ série e 62,2 pontos na $3^{\underline{a}}$ série. Ou seja, a pontuação dos ouvintes na $3^{\underline{a}}$ série $(62,2)$ foi aproximadamente equivalente à pontuação dos surdos na $1^{\underline{a}}$ série do ensino médio $(61,4)$. Como a pontuação média dos surdos na $1^{\underline{a}}$ série do ensino médio foi equivalente à dos ouvintes na $3^{\underline{\underline{a}}}$ série do ensino fundamental, podem ser feitas comparações entre as amostras, embora elas sejam de níveis escolares diferentes, para a análise dos desempenhos nos sete diferentes tipos de itens do TCLP.

Em termos de concordâncias entre os padrões de surdos e ouvintes, foi observado que, tanto para surdos quanto para ouvintes, as pontuações em PE e em VS foram maiores do que em VV, VF e PH. Em termos de discrepâncias entre os padrões de leitura de surdos e ouvintes, foram observadas quatro diferenças. A primeira diferença foi entre VV e $\mathrm{PH}$ : para os ouvintes, o acerto em VV foi maior que em $\mathrm{PH}$; para os surdos, o inverso. A segunda foi entre VV e VF: para os ouvintes, o acerto em VV foi maior que em VF; para os surdos, o inverso. A terceira diferença foi entre VF e PH: para os ouvintes, o acerto em VF foi maior que em $\mathrm{PH}$; para os surdos, o inverso. Finalmente, a quarta diferença foi entre PE e VS: para os ouvintes, o acerto em PE foi maior que em VS; para os surdos, o inverso.

Esses achados corroboram a noção de que, porque empregam a estratégia de reconhecimento visual direto, os leitores surdos são menos suscetíveis do que os leitores ouvintes a deixar-se enganar pela homofonia de pseudopalavras (i.e., semelhança entre a imagem fonológica resultante da decodificação grafofonêmica de pseudopalavras e a imagem resultante da decodificação grafofonêmica de palavras reais). Porém, são mais suscetíveis do que os leitores ouvintes a deixar-se enganar pela semelhança visual entre pseudopalavras e palavras realmente pertencentes ao léxico ortográfico (i.e., pela semelhança entre a imagem ortográfica das pseudopalavras e as das palavras reais). É possível que a maior facilidade dos leitores ouvintes em detectar a incorreção de pseudopalavras estranhas em relação à incorreção de palavras semanticamente incorretas se deva ao fato de que apenas para eles, ouvintes, é que as pseudopalavras estranhas produzem formas fonológicas bizarras quando decodificadas, sendo que as palavras semanticamente incorretas ainda produzem formas fonológicas familiares quando decodificadas.

Assim, foram observadas diversas duplas dissociações entre as estratégias de processamento ideovisual e fonológico empregadas por leitores surdos e leitores ouvintes. Por exemplo, em surdos, foi observada uma clara superioridade na correta rejeição de $\mathrm{PH}$ do que VF do que de VV (i.e., de PH do que de VF, de VF do que de VV, e de PH do que de VV), e na correta rejeição de VS do que de PE. De modo radicalmente oposto, em ouvintes, foi identificada uma clara superioridade na correta rejeição de VV do que de VF do que de PH (i.e., de VV do que de VF, de VF do que de $\mathrm{PH}$, e de VV do que de $\mathrm{PH}$ ), e na correta rejeição de PE do que de VS. A mais clara e relevante dissociação entre processos ideovisuais e fonológicos

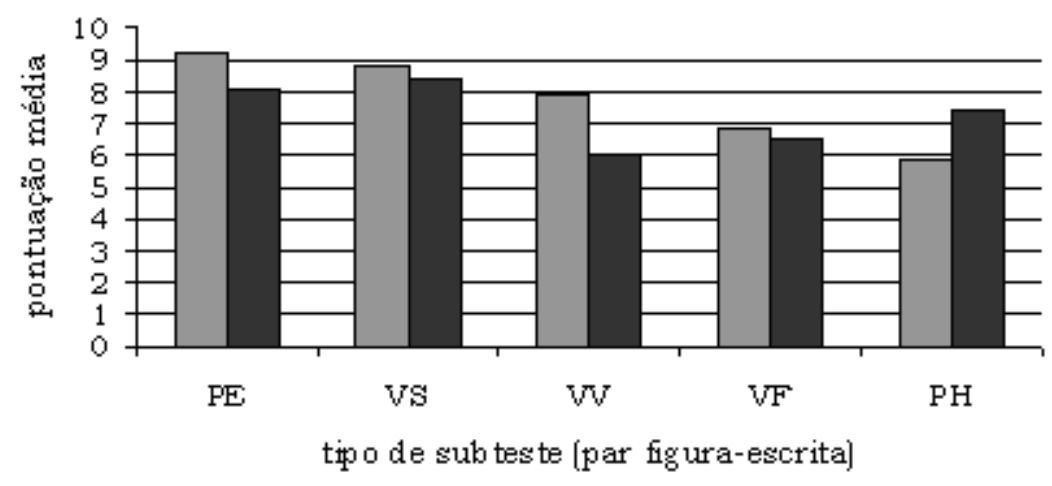

$\square$ ouvintes 1 a. -3 a. Séries

surdos 1 a. $-8 \mathrm{a}$. Séries

Figura 2. Pontuação média nos cinco tipos de subteste na amostra de mil leitores ouvintes de $1^{\underline{a}}$ a $3^{\underline{a}}$ série do estudo de A. Capovilla e F. Capovilla (no prelo a) e na presente amostra de 740 leitores surdos de $1^{\underline{a}}$ a $8^{\underline{a}}$ séries. 
entre leitores surdos e ouvintes foi encontrada entre VV e PH. Nessa comparação, os surdos foram superiores aos ouvintes na correta rejeição de $\mathrm{PH}$ do que de $\mathrm{VV}$, ao passo que os ouvintes foram superiores aos surdos na correta rejeição de VV do que de PH. Tais dados revelam quão dependente de mecanismos visuais diretos de reconhecimento e acesso ao significado é a leitura do surdo. Na ausência do mecanismo de conferência perilexical, o mecanismo de reconhecimento visual direto freqüentemente se limita ao nível logográfico, resultando daí alta freqüência de paralexias, em especial em palavras de baixa ocorrência no léxico do leitor surdo.

\section{Discussão}

Este estudo forneceu uma avaliação preliminar da competência de leitura de itens isolados por crianças, jovens e adultos surdos de 6 a 45 anos de idade, estudantes da $1^{\underline{a}}$ série do ensino fundamental até a $1^{\underline{a}}$ série do ensino médio. O estudo apresentou o desempenho médio nessa faixa escolar, e descreveu o padrão de distribuição de escores nos subtestes. Essa amostra pode ser considerada como sendo composta principalmente por surdos sinalizadores, visto que, dos 805 participantes, 700 estudavam em escolas especiais para surdos que ministram aulas em Libras.

A análise dos desempenhos nos vários tipos de par figura-palavra escrita foi conduzida com os 740 participantes de $1^{\underline{a}}$ a $8^{\underline{a}}$ série que tinham idade conhecida. Tais pares demandam diferentes habilidades de decodificação grafofonêmica, reconhecimento visual direto da forma ortográfica e acesso ao significado. A análise revelou como os surdos dessa amostra, em sua maior parte sinalizadores, empregam as rotas logográfica, perilexical e lexical no processamento da leitura de itens psicolingüísticos isolados, como palavras e pseudopalavras.

Exceto pela decodificação grafoquirêmica de palavras pouco familiares por meio de soletração digital (Capovilla \& Raphael, 2001), examinandos sinalizadores com surdez profunda pré-lingual e perilingual usualmente não decodificam grafofonemicamente o que lêem, a menos que sejam oralizados. Ao ler palavras cuja forma ortográfica é relativamente familiar, esses examinandos tendem a confiar mais no reconhecimento visual direto da forma ortográfica global das palavras escritas para conseguir obter acesso direto ao significado. Contudo, tal processamento logográfico é capaz de resolver apenas alguns dos problemas de aquisição de leitura.

Dois achados iniciais revelam dois tipos de problemas envolvidos na aquisição de leitura que são passíveis de tratamento por esse tipo de processamento visual global de palavras que os surdos tendem a usar: (a) O desempenho na identificação de disparidade entre o significado de palavras escritas e o de figuras a elas emparelhadas tende a ser bastante bom, já que tais disparidades semânticas são facilmente detectáveis por esse processo. De fato, o desempenho em palavras com trocas semânticas (VS) foi muito bom (8,2 pontos); (b) O desempenho na identificação da incorreção de pseudopalavras com formas ortográficas muito diferentes das formas ortográficas de palavras conhecidas também tende a ser bom, já que essas formas ortográficas claramente distintas são facilmente detectáveis por esse mesmo processo de reconhecimento visual global, de que eles dispõem. De fato, seu desempenho em pseudopalavras visualmente bem distintas (PE) também foi muito bom (7,8 pontos).

Contudo, em sinalizadores não-oralizados e com surdez profunda pré-lingual ou perilingual esse processamento logográfico é usualmente desacompanhado da retificação pela decodificação, já que esses leitores carecem de formas fonológicas armazenadas no léxico com que comparar as formas eventualmente construídas por decodificação grafoquirêmica (i.e., soletração digital das palavras escritas). Enquanto os leitores ouvintes podem usar a decodificação grafofonêmica e conferir se a forma fonológica, que é produzida pela decodificação, soa como a forma fonológica de uma das palavras familiares que se encontram armazenadas em seu léxico fonológico, os leitores não-oralizados e com surdez profunda pré-lingual ou perilingual tendem a limitar-se ao reconhecimento visual global e quase ideográfico das palavras (Zaidel, 1981; Zaidel \& Peters, 1981) baseado na imagem ortográfica global da palavra escrita, já que não possuem formas fonológicas armazenadas em seu léxico com as quais comparar as formas eventualmente decodificadas.

Como o código alfabético não pode ser bem adquirido por meio desse tipo de processamento ideográfico (cf. Capovilla \& Capovilla, 2004c; Freebody \& Byrne, 1988), a aprendizagem de leitura que foi restrita a esse tipo de processamento tende a limitar-se a um padrão típico das séries iniciais. De fato, conforme Prillwitz (1990), o nível de leitura típico de estudantes não-oralizados e com surdez profunda pré-lingual ou perilingual é de $3^{\underline{a}}$ série do ensino fundamental. Incapazes de decodificação grafofonêmica e destituídos do léxico de imagens fonológicas de palavras ouvidas conhecidas, tais leitores surdos não têm como detectar trocas sutis em letras e ordens de letras, e dependem quase que exclusivamente do reconhecimento visual de palavras baseado na forma global das palavras escritas.

Este estudo também demonstrou um terceiro problema, teoricamente já esperado em leitores surdos: a identificação de incorreção de pseudopalavras com formas ortográficas visualmente semelhantes às das palavras conhecidas (VV) foi especialmente ruim, já que essas trocas ortográficas visuais não são facilmente detectáveis pelo processo de reconhecimento visual global. De fato, o desempenho em pseudopalavras visualmente semelhantes com trocas de natureza visual (VV) foi bastante baixo (5,8 pontos), e inferior ao de leitores ouvintes.

No entanto, leitores surdos também podem ter vantagens e detectar certos tipos de malformação de escrita melhor do que alfabetizandos ouvintes. O processo de decodificação grafofonêmica que as crianças ouvintes alfabetizandas ou recém-alfabetizadas usam quando lêem faz com que deixem de perceber palavras malformadas que 
contêm trocas de natureza fonológica, especialmente quando elas são exatamente homófonas às palavras conhecidas (PH). Enquanto o aprendiz de leitor ouvinte pode deixar-se levar pela homofonia, o aprendiz de leitor não-oralizado com surdez profunda pré-lingual e perilingual, porque não ouve e não tem um léxico fonológico que lhe permita "ler de ouvido”, não se deixa iludir do mesmo modo pela homofonia, e acaba por detectar trocas baseadas na homofonia mais facilmente do que o alfabetizando ouvinte. Isso explica o quarto achado do estudo, ou seja, o bom desempenho de leitores surdos em detectar a incorreção de pseudopalavras com formas ortográficas claramente distintas mas que são, para os ouvintes, homófonas às palavras conhecidas. De fato, sua detecção da incorreção de pseudopalavras homófonas foi acima da média e quase tão boa quanto a sua detecção da incorreção de pseudopalavras estranhas (7,1 pontos). Isso mostra a prevalência da leitura visual logográfica no surdo, que se concentra no acesso ao significado.

Foram, ainda, observadas diversas duplas dissociações entre as estratégias de processamento ideovisual e fonológico empregadas por leitores surdos de um lado e por leitores ouvintes de outro. Por exemplo, surdos identificaram melhor incorreções em $\mathrm{PH}$ do que em VF, em VF do que em VV, e em VS do que em PE. De modo oposto, ouvintes identificaram incorreções mais bem em VV do que em VF, em VF do que em PH, e em PE do que em VS. A mais clara e relevante dissociação entre processos ideovisuais e fonológicos entre leitores surdos e ouvintes foi encontrada entre VV e $\mathrm{PH}$, em que surdos foram superiores a ouvintes na identificação correta de PH mais do que de VV, ao passo que ouvintes foram superiores a surdos na identificação de VV do que de PH.

Em suma, o estudo revelou quão dependente de mecanismos visuais diretos de reconhecimento e acesso ao significado é a leitura do surdo. Desacompanhado da conferência perilexical da decodificação, o reconhecimento visual direto isolado tende a limitar a leitura ao nível logográfico, produzindo freqüentes paralexias, em especial em palavras de baixa ocorrência no léxico do leitor. A partir da presente análise das estratégias logográfica, perilexical e lexical no leitor surdo e da disponibilização de um instrumento para avaliar leitura em surdos, este estudo poderá ensejar alfabetização e escolarização mais competentes. A introdução de TCLP como instrumento de avaliação de competência e processos de leitura de surdos deverá contribuir para comparar a eficácia relativa de diferentes procedimentos de ensino, permitindo descobrir quais são os procedimentos mais adequados para estudantes surdos com diferentes características. A busca desse cruzamento entre os diversos procedimentos de ensino e as diferentes características dos estudantes constitui uma abordagem matricial que concilia rigor metodológico e respeito ao educando, permitindo ultrapassar a crença ingênua em panacéias e resgatar o que há de útil e produtivo nas mais variadas práticas de ensino de surdos que têm sido adotadas e esquecidas ao sabor da moda ao longo dos últimos séculos de história.

\section{Referências}

Adams, M. J. (1990). Beginning to read: thinking and learning about print. Cambridge: The MIT Press.

Boder, E. (1973). Developmental dyslexia: a diagnostic approach based on three atypical reading-spelling patterns. Developmental Medicine and Child Neurology, 15, 663-687.

Braibant, J. M. (1997). A decodificação e a compreensão: dois componentes essenciais da leitura no $2^{\underline{0}}$ ano primário. In J. Grégoire \& B. Piérart (Orgs.), Avaliação dos problemas de leitura: os novos modelos teóricos e suas implicações diagnósticas (pp. 166-187). Porto Alegre: Artes Médicas.

Capovilla, A. G. S., \& Capovilla, F. C. (2004a). Alfabetização: método fônico ( $3^{\underline{a}}$ ed.). São Paulo: Memnon, Fapesp, Capes, CNPq.

Capovilla, A. G. S., \& Capovilla, F. C. (2004b). Etiologia, avaliação e intervenção em dislexia do desenvolvimento. In F. C. Capovilla (Org.), Neuropsicologia e aprendizagem: uma abordagem multidisciplinar ( $2^{\underline{a}}$ ed., pp. 49-76). São Paulo: Memnon, Capes, SBNp.

Capovilla, A. G. S., \& Capovilla, F. C. (2004c). Problemas de leitura e escrita: como identificar, prevenir e remediar numa abordagem fônica ( $4^{\underline{a}}$ ed.). São Paulo: Memnon, Fapesp, Capes, CNPq.

Capovilla, A. G. S., \& Capovilla, F. C. (no prelo a). Padrão de leitura em mil leitores ouvintes de $1^{\mathrm{a}}$ a $3^{\mathrm{a}}$ série do ensino fundamental no TCLP: processamentos ideovisual, fonológico, e semântico. In F. Capovilla \& A. Capovilla (Orgs.), Compêndio de avaliação de desenvolvimento da linguagem oral, escrita e de sinais. São Paulo: Editora da Universidade de São Paulo.

Capovilla, A. G. S., \& Capovilla, F. C. (no prelo b). Prova de consciência fonológica por escolha de figuras: para avaliação coletiva em classe escolar, e individual em paralisia cerebral. In F. Capovilla \& A. Capovilla (Orgs.), Compêndio de avaliação de desenvolvimento da linguagem oral, escrita e de sinais. São Paulo: Editora da Universidade de São Paulo.

Capovilla, A. G. S., Gütschow, C. R. D., \& Capovilla, F. C. (2003). Instrumentos de avaliação de habilidades cognitivas relacionadas à aquisição de leitura e escrita: análise de validade e fidedignidade. In A. G. S. Capovilla (Org.), Avaliação e intervenção em habilidades metafonológicas e de leitura e escrita (pp. 70-90). São Paulo: Memnon.

Capovilla, A. G. S., Machalous, N., \& Capovilla, F. C. (2003). Leitura de crianças bilíngües: uso das rotas fonológica e lexical em português e alemão. In M. R. Maluf (Org.), Metalinguagem e aquisição da escrita (pp. 185216). São Paulo: Casa do Psicólogo.

Capovilla, A. G. S., Smythe, I., Capovilla, F. C., \& Everatt, J. (2001). Adaptação brasileira do International Dyslexia Test: perfil cognitivo de crianças com escrita pobre. Temas sobre Desenvolvimento, 10(57), 30-37.

Capovilla, F. C., \& Capovilla, A. G. S. (1997). Desenvolvimento lingüístico da criança dos dois aos seis anos: tradução e estandardização do Peabody Picture Vocabulary Test de Dunn \& Dunn, e da Language Development Survey de Rescorla. Ciência Cognitiva: Teoria, Pesquisa e Aplicação, 1(1), 353-380.

Capovilla, F. C., \& Capovilla, A. G. S. (2001). Compreendendo a natureza dos problemas de aquisição de leitura e escrita: mapeando o envolvimento de distúrbios cognitivos de discriminação fonológica, velocidade de processamento e memória fonológica. Cadernos de Psicopedagogia, 1(1), 14-37.

Capovilla, F. C., \& Capovilla, A. G. S. (2004). Research on the role of phonology, orthography and cognitive skills upon reading, spelling and dyslexia in Brazilian Portuguese. In I. Smythe, J. Everatt, \& R. Salter (Orgs.), International handbook of dyslexia: a cross-language comparison and practice guide (pp. 159-172). Londres: John Wiley \& Sons.

Capovilla, F. C., Nunes, L. R. O. P., Nogueira, D., Nunes, D., Araújo, I., Bernat, A. B., \& Capovilla, A. G. S. (1997). Análise da validade concorrente do Teste de Vocabulário por Imagens Peabody por comparação com o desempenho escolar de pré-escola a $8^{\underline{a}}$ série: amostra fluminense. Ciência Cognitiva: Teoria, Pesquisa e Aplicação, 1(2), 533-560. 
Capovilla, F. C., \& Raphael, W. D. (2001). Alfabeto manual da Libras, números em Libras, e formas de mão usadas em Libras. In F. C. Capovilla, \& W. D. Raphael (Orgs.), Dicionário enciclopédico ilustrado trilíngüe da Língua de Sinais Brasileira. Volume I: Sinais de A a L (Vol. 1, 2ª ed., pp. 51-54). São Paulo: Editora da Universidade de São Paulo, Imprensa Oficial do Estado de São Paulo.

Capovilla, F. C., Viggiano, K. Q., Capovilla, A. G. S., Raphael, W. D., Mauricio, A. C., \& Bidá, M. C. P. R. (no prelo). Como avaliar o desenvolvimento da competência de leitura silenciosa de palavras em surdos do ensino fundamental ao médio, e analisar processos de reconhecimento e decodificação: versão original do Teste de Competência de Leitura de Palavras. In F. C. Capovilla \& W. D. Raphael (Orgs.), Enciclopédia da Língua de Sinais Brasileira: o mundo do surdo em Libras, Vol. 1: Sinais da Libras e o universo da educação; e como avaliar o desenvolvimento da competência de leitura de palavras (processos de reconhecimento e decodificação) em escolares surdos do Ensino Fundamental ao Médio. São Paulo: Editora da Universidade de São Paulo, Imprensa Oficial do Estado de São Paulo, Vitae, Capes, CNPq, Fapesp.

Cardoso-Martins, C., Capovilla, F. C., Gombert, J. E., Oliveira, J. B. A., Morais, J. C. J., Adams, M. J., \& Beard, R. B. (2003). Alfabetização infantil: os novos caminhos. Brasília: Congresso Nacional.

Clark, M. D., Marschark, M., \& Karchmer, M. (2001). (Orgs.). Context, cognition, and deafness. Washington: Gallaudet University Press.

Freebody, P., \& Byrne, B. (1988). Word reading strategies in elementary school children: relationships to comprehension, reading time, and phonemic awareness. Reading Research Quarterly, 24, 441-453.

Frith, U. (1990). Dyslexia as a developmental disorder of language. Londres: MRC, Cognitive Development Unit.

Gillespie, C. W., \& Twardosz, S. (1996). Survey of literacy environments and practices in residences at schools for the deaf. American Annals of the Deaf, 141(3), 224-230.
Gillespie, C. W., \& Twardosz, S. (1997). A group storybook-reading intervention with children at a residential school for the deaf. American Annals of the Deaf, 142(4), 320-332.

Hoggan, K. C., \& Strong, C. J. (1994). The magic of “once upon a time”: narrative teaching strategies. Language, Speech, and Hearing Services in Schools, 25(2), 76-89.

Karchmer, M. A., Allen, T. E., Petersen, L. M., \& Quaynor, A. (1982). Hearingimpaired children and youth in Canada: student characteristics in relation to manual communication patterns in four special education settings. American Annals of the Deaf, 127(2), 89-104.

Khomsi, A. (1997). A propósito de estratégias de compensação nas crianças disléxicas. In J. Grégoire \& B. Piérart (Orgs.), Avaliação dos problemas de leitura: os novos modelos teóricos e suas implicações diagnósticas (pp. 203-214). Porto Alegre: Artes Médicas.

Luetke-Stahlman, B., Hayes, P. L., \& Nielsen, D. C. (1996). Essential practices as adults read to meet the needs of deaf or hard of hearing students. American Annals of the Deaf, 141(4), 309-320.

Morton, J. (1989). An information-processing account of reading acquisition. In A. M. Galaburda (Org.), From reading to neurons: issues in the biology of language and cognition (pp. 43-66). Cambridge: The MIT Press.

Prillwitz, S. (1990). The long road towards bilingualism of the deaf in the German-speaking area. In S. Prillwitz, \& T. Vollhaber (Orgs.), Sign Language research and application: international studies on sign language and communication of the deaf (Vol. 13, pp. 13-27). Hamburgo: Signum.

Zaidel, E. (1981). Reading by the right hemisphere: a perspective from the normal brain. In U. Kirk (Org.), Neuropsychology of language and spelling. Nova York: Academic.

Zaidel, E., \& Peters, A. M. (1981). Phonological encoding and ideographic reading by the disconnected right hemisphere: two case studies. Brain and Language, 14(2), 205-234.

1 Esta pesquisa foi financiada pelo CNPq, com bolsa de produtividade em pesquisa para os dois primeiros autores e bolsa de mestrado para os demais três autores, e com auxílio da Capes, da Fundação Vitae e da Fapesp.

Fernando Capovilla, doutor em Psicologia Experimental pela Temple University (EUA) e livre-docente em Psicologia Clínica pela Universidade de São Paulo, é professor no Instituto de Psicologia da Universidade de São Paulo. Endereço para correspondência: Av. Prof. Mello Moraes, 1721; São Paulo, SP; CEP 05508-900; Tel: (11) 3091-4001. Fax (11) 3091-4909. E-mail: capovilla@usp.br Alessandra Gotuzo Seabra Capovilla, doutora em Psicologia Experimental pela Universidade de São Paulo, é professora no Programa de Estudos Pós-Graduados em Psicologia da Universidade São Francisco. Keila Viggiano é mestre em Psicologia Experimental pela Universidade de São Paulo. Aline Mauricio é mestranda em Psicologia Experimental pela Universidade de São Paulo. Márcia Bidá é mestranda em Psicologia Experimental pela Universidade de São Paulo. 